$\xi=-1$

\title{
Backscattering coefficient measurement and land use land cover classification using ENVI SAT ASAR data
}

\author{
K.V. Ramana Rao ${ }^{1 *}$, Prof. P. Rajesh Kumar ${ }^{2}$ \\ ${ }^{I}$ Department of ECE, VIEW, Visakhapatnam, Andhra Pradesh, India \\ ${ }^{2}$ Department of ECE, A.U.C.E, Visakhapatnam, Andhra Pradesh, India \\ *Corresponding author E-mail: ramanadeepu@yahoo.co.in
}

\begin{abstract}
The polarimetric SAR data of the space borne sensor, ENVISAT-ASAR (Environmental Satellite - Academic \& Science Astronomy \& Space Science) has been used for the land use land cover classification of the study area. It was an earth observing satellite operated by the European Space Agency (ESA). Its mission was to observe the earth and monitor critical aspects of the environment such as climatic changes on the earth at the local, regional and global levels. The data set of this sensor is a dual co-polarization amplitude data consisting of $\mathrm{HH}$ and VV channels. Initially various incidence angle images such as sigma naught, beta naught and gamma naught have been generated for both $\mathrm{HH}$ and VV polarizations. Then the backscattering coefficients of different features such as water, bare soil, vegetation and urban have been calculated. The backscattering coefficient values of the HH polarization are high compared to the values that are obtained with VV polarization. Then the land use land cover classification has been done by implementing different supervised classification algorithms. These classification methods are Parallelepiped, Minimum Distance, Mahalanobis, Maximum Likelihood, Binary Coding and Support Vector Machine. Then the accuracy measurements have been done for all these classification methods. In the present study the accuracy results obtained with the supervised Support Vector Machine classification algorithm are more compared to the accuracy results obtained with the other supervised classification methods.
\end{abstract}

Keywords: Support Vector Machine; Back scattering image; Polarization; ENVISAT-ASAR; Speckle; Classification.

\section{Introduction}

The continuous monitoring of the earth surface has been playing a vital role since recent past because of the increasing population and industrialization all over the world. Especially the land use land cover information of different areas has got lot of importance for various authorities such as urban planning and development. The enhanced features of ENVISAT-ASAR offer more reliable polarimetric SAR data that can be used for various applications of earth surface monitoring like land use land cover classification, oceanography, preparing imaging maps, study of soil moisture, seasonal crops and forestry etc [1]. This is achieved by periodically stepping the antenna beam to the neighboring sub swaths (in the range direction). It is operated in C-band with 6-beam ScanSAR mode and provides the amplitude data of dual $\mathrm{HH}$ and VV polarization. Since this data is affected with speckle noise, the Gamma filter of 5X5 size is used to remove the unwanted noise. Geometric correction and geo-referencing techniques are applied to polarimetric SAR data sets. Since the radar backscattering [2] is a function of various parameters like incidence angle, polarization, and frequency of the radar sensor and as well as the properties of the target such as geometry, roughness and dielectric constant, it is initially proposed to generate the backscattering coefficients of the available data in the present work. These back scattering coefficients are calculated for various features using both dual polarization $\mathrm{HH}$ and VV data sets. Land use land cover classification of the study area is performed with various supervised classification techniques [3].

\section{Backscattering coefficients of ENVISAT- ASAR}

The radar backscattering coefficient $\operatorname{Sigma}_{0}\left(\sigma_{0}\right)$ is related to the radar brightness $\operatorname{Beta}_{0}\left(\beta_{0}\right)$ as follows:

The relation between different backscattering coefficients of the SAR data is given by

$\operatorname{Sigma}_{0}=\operatorname{Beta}_{0} \cdot \sin \varnothing$

Here, $\varnothing$ is representing the local incidence angle. $\operatorname{Sigma}_{0}\left(\sigma_{0}\right)$ can be converted into decibels using the following formula,

$\operatorname{Sigma}_{0}(\mathrm{~dB})=10 \log _{10}$ Sigma 0

Radiometric calibration is to be done in order to convert the radar images into corresponding backscattering values. The digital number (DN) can be converted into either Sigmao image or Betao image which can be represented in terms of decibels. The incidence angle information of the pixels and scene centre can be obtained from the available Meta data using which the Sigma image can be calculated. The digital number can be calculated from square root of squares of real and imaginary values of SLC (Single Look Complex) data, if SLC data has been considered [4]. The backscattering coefficient of ENVISAT-ASAR data can be calculated using the formula

$\operatorname{Sigma}_{0}(\mathrm{~dB})=\operatorname{Beta}_{0}(\mathrm{~dB})+10 \log _{10}\left(\sin \left(\mathrm{I}_{\mathrm{ip}}\right) / \sin \left(\mathrm{I}_{\mathrm{isc}}\right)\right)$ 
and

$\operatorname{Beta}_{0}(\mathrm{~dB})=20 \log _{10}(\mathrm{DN})-\mathrm{K}(\mathrm{dB})$

Where ' $\mathrm{I}_{\text {ip }}$ ' means incidence angle of the particular pixel, ' $\mathrm{I}_{\mathrm{isc}}$ ' means incidence angle of the scene centre and ' $\mathrm{K}$ ' is the calibration constant.

$\mathrm{K}=74.819153 \mathrm{~dB}$ for $\mathrm{HH}$ polarization of the scene.

$\mathrm{K}=86.040230 \mathrm{~dB}$ for $\mathrm{VV}$ polarization of the scene.

\section{Study Area}

Visakhapatnam city is selected as the study area which is the district head quarters of Visakhapatnam District located in the State of Andhra Pradesh, India. An area of about 621.52 sq. km covering Visakhapatnam city and its surroundings is chosen for study purpose. Visakhapatnam city lies between $17^{0} 10^{\prime}$ to $17^{0} 56^{\prime} \mathrm{N}$ latitudes and $83^{\circ} 08^{\prime}$ to $83^{\circ} 40^{\prime} \mathrm{E}$ longitudes (fig 1.). The northern boundary of this city is some part of Orissa State and some part of Vizianagaram district, southern boundary is East Godavari district, western boundary is Orissa stateandeastern boundary is Bay of Bengal. This city has been selected as one of the smart cities in India and lot of development has been taking place since recent past. This city has been affected by a natural calamity hudhud in the year 2014. The main advantage of this city is availability of natural port, many public sector undertaking companies and other private industries.

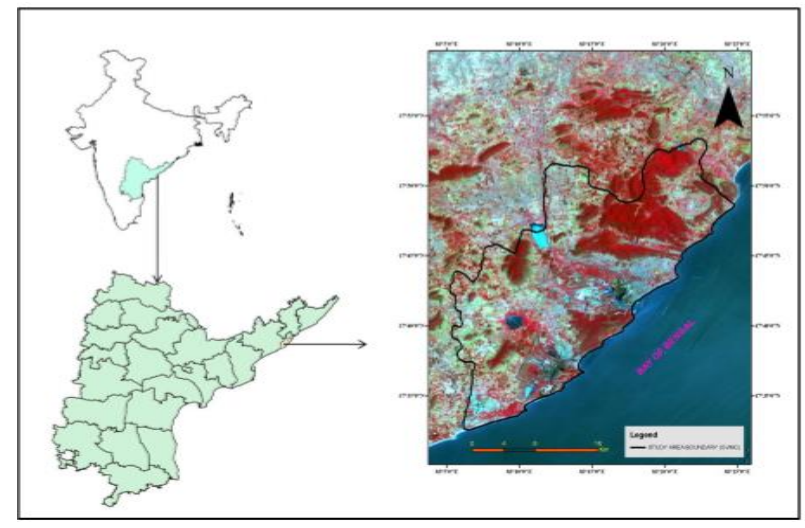

Fig. 1: Location Map of the Study Area.

\section{Data used}

In the present study, the dual polarimetric SAR data (HH \& VV) of ENVISAT-ASAR is used which is provided by the ESA (European Space Agency). These SAR data sets of medium resolution mode are acquired on April 03, 2011 over the city of Visakhapatnam, India with central latitude of $17.41 \mathrm{~N}$, central longitude of 83.23E, with dual polarization (co-polarization) $\mathrm{HH}$ and $\mathrm{VV}$ modes are available. The data sets are in C-band with a wavelength of $5.6 \mathrm{~cm}$, the spatial resolution is of $30 \mathrm{~m}$ and the pixel spacing is of $12.5 \mathrm{~m}$. In the study area, the incidence angle of the images is varied between $15^{\circ}$ to $45.2^{\circ}$. In this work, initially preprocessing (radiometric calibration and geo-referencing) of the polarimetric SAR data is done. Then the linear data is converted into decibels. Speckle is removed with Gamma filter. Sigma, Beta 0 and Gamma images are generated. The backscattering coefficients are analysed. Finally various classification algorithms are implemented and respective accuracies are calculated.

\subsection{Pre-processing}

The polarimetric SAR raw data set provided by the ENVISATASAR sensor has been pre-processed by adopting the prescribed methodology as shown in fig. 2 in order to make it suitable for obtaining the classification analysis of the study area using various land use land cover classification algorithms. Pre-processing of this amplitude data of ENVISAT-ASAR sensor includes speckle removal, slant to ground range conversion, georeferncing the data, and generation of the backscattering coefficients. SNAP software has been used for pre-processing of the ENVISAT-ASAR level-1 dual polarimetric SAR data. The amplitude data with dual polarization $\mathrm{HH}$ and $\mathrm{VV}$ datasets are imported to the SNAP (Sentinels Application Platform) software for converting linear data into decibels and then Gamma filter of 5X5 kernel size is used to remove the speckle noise. The noise in the near and far ranges causes the variations in the brightness of the polarimetric SAR data [5].The slant range data is converted to ground range data using the geometric corrections and then UTM/WGS 84 projection is used for the geo-referencing of the polarimetric SAR data. Then the Sigman image is generated and converted into a geo-tiff format. The Sigma image is imported through ARC-GIS to provide the standard deviation.

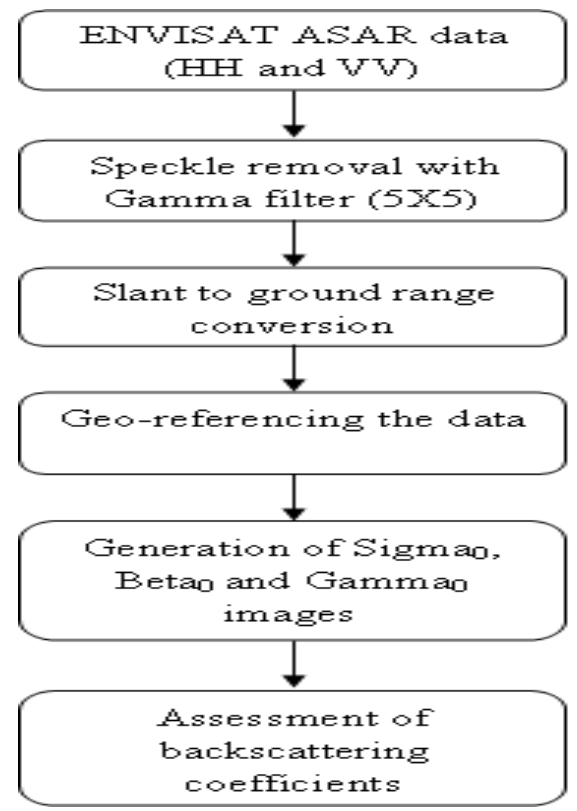

Fig. 2:Pre-Processing Steps for ENVISAT ASAR Data.

\section{Results and discussions}

The medium resolution scanSAR mode data has been taken for generating and analysing the back scattering phenomenon. The information about the data taken for this purpose is shown in the table 1 . The steps involved in this process have been mentioned in fig. 2. The Betao image, Sigma image and Gamma output image of $\mathrm{HH}$ polarization have been shown in fig. 3 for various textures like water, settlement, agriculture and bare soil fields [6]. The Betao image, Sigman image and Gamma output image of VV polarization have been shown in fig. 4 for various textures like water, settlement, agriculture and barren fields [7].
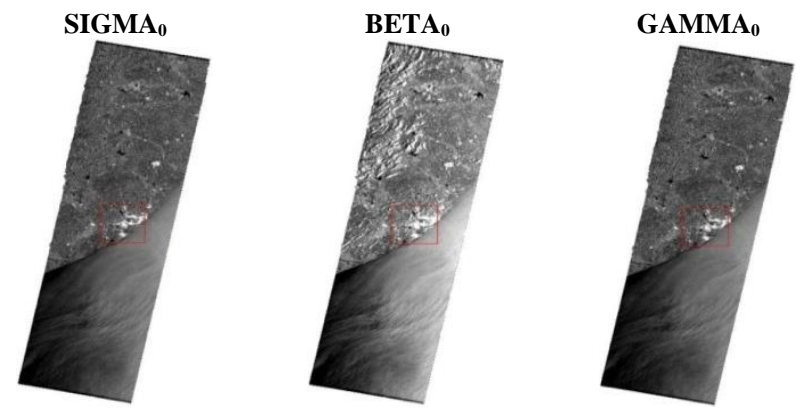

Fig. 3: Comparison of Incidence Angle Image, Sigma ${ }_{0}, B^{2} a_{0}$ and Gam$\mathrm{ma}_{0}$ Images for HH Polarization. 

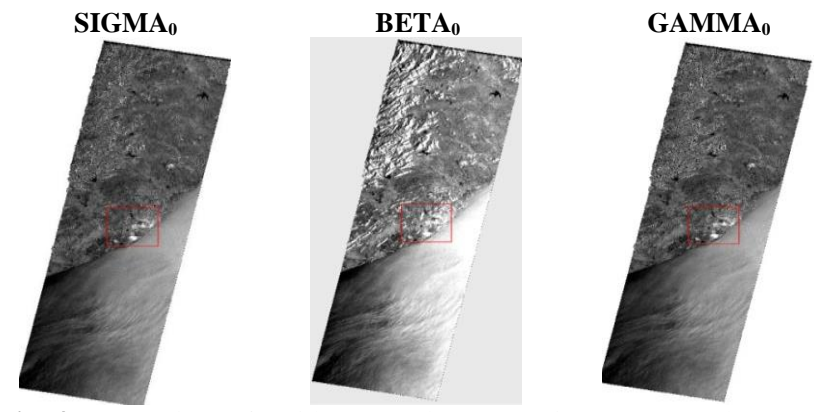

Fig. 4: Comparison of Incidence Angle Image, Sigma $_{0}, B \mathrm{Beta}_{0}$ and $\mathrm{Gamma}_{0}$ Images for VV Polarization.
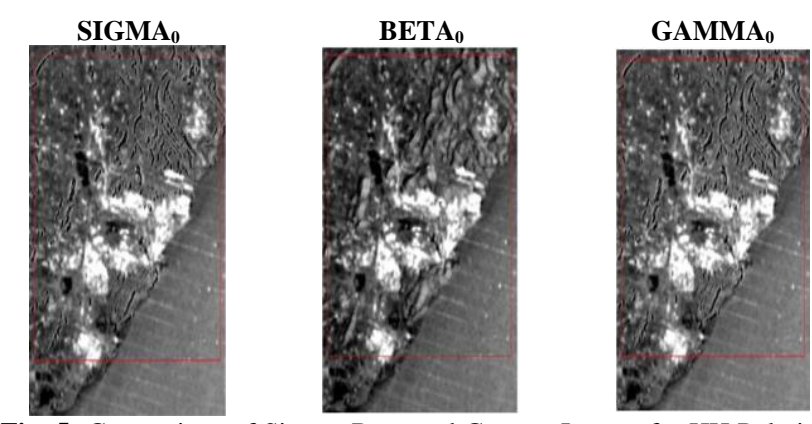

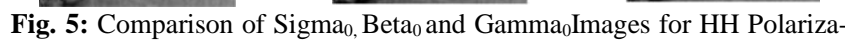
tion.
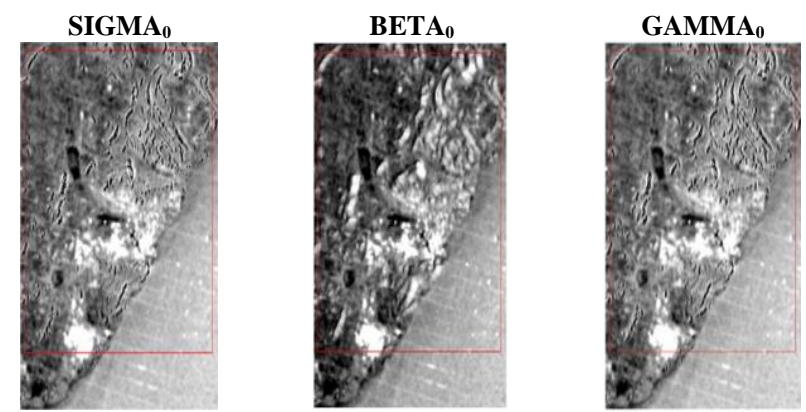

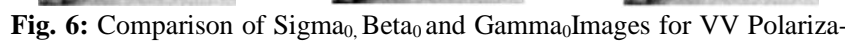
tion.

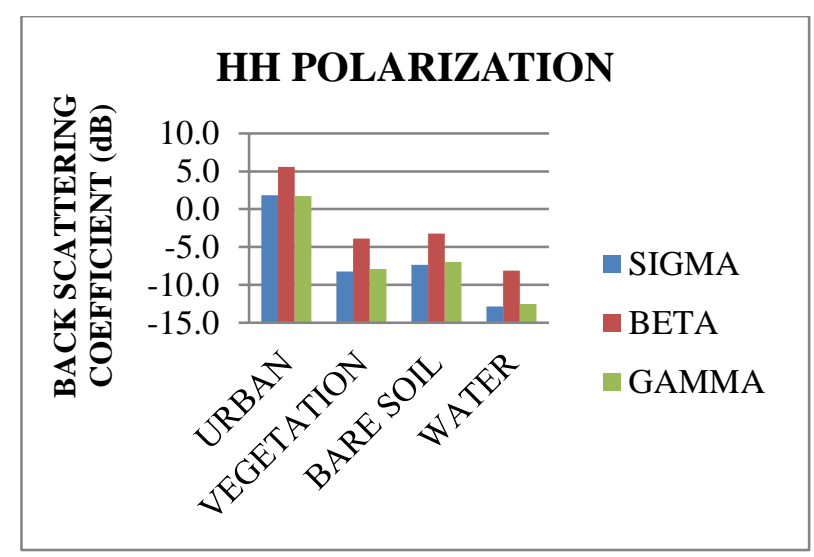

Fig. 7: Comparison of Backscattering Coefficient Values for $\operatorname{Sigma}_{0}$ Beta $_{0}$ and $\mathrm{Gamma}_{0}$ in $\mathrm{HH}$ Polarization.

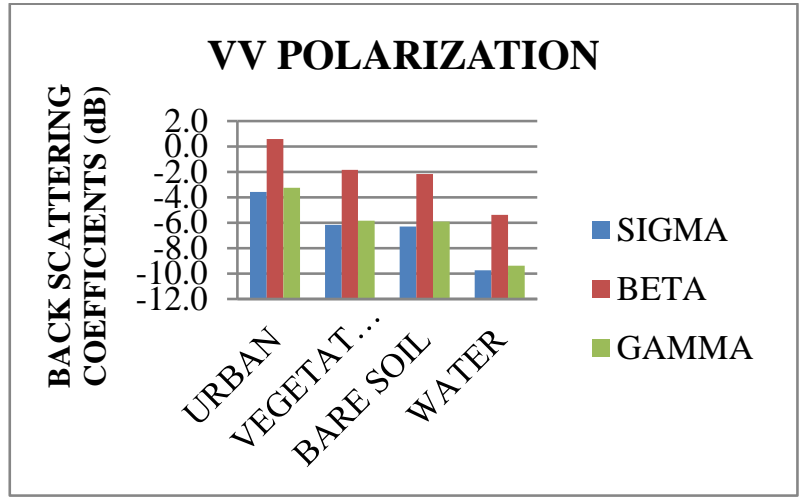

Fig. 8: Comparison of Backscattering Coefficient Values for Sigma Beta $_{0}$

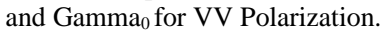

(A)

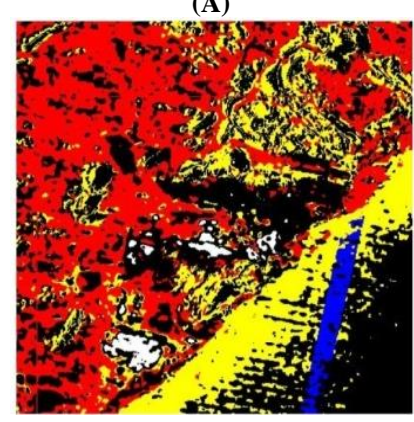

(C)

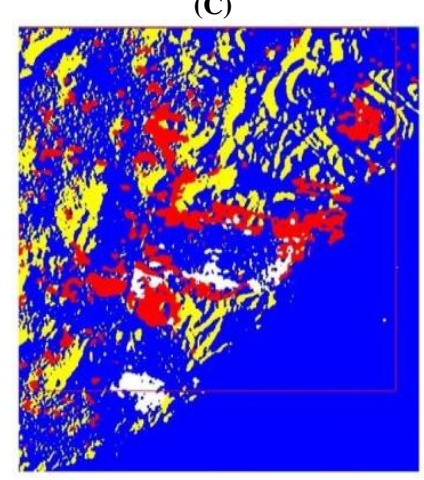

(E)

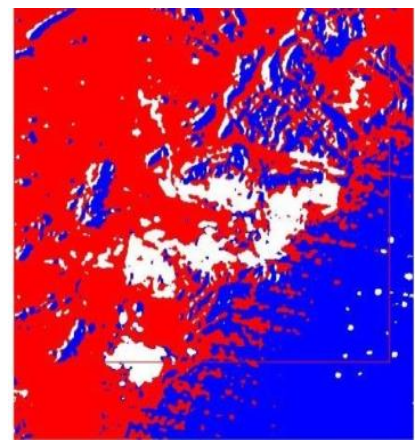

Fig. 9: Different Classification Images (A) Parallelpiped Classification (B) Minimum Distance Classification (C) Mahalanobis Distance Classification

(D) Maximum Likelihood Classification (E) Binary Coding Classification (F) Support Vector Machine Classification.

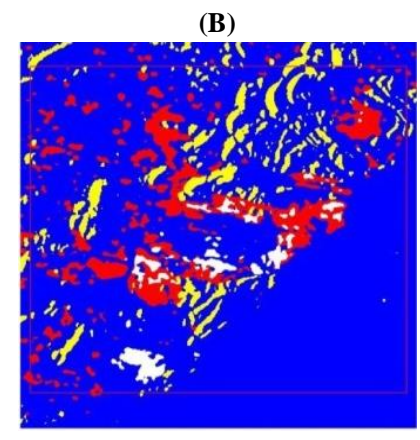

(D)

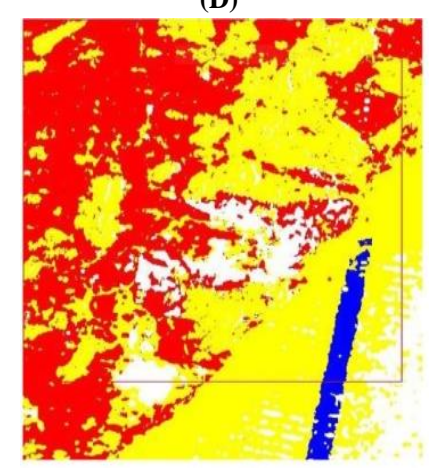

(F)

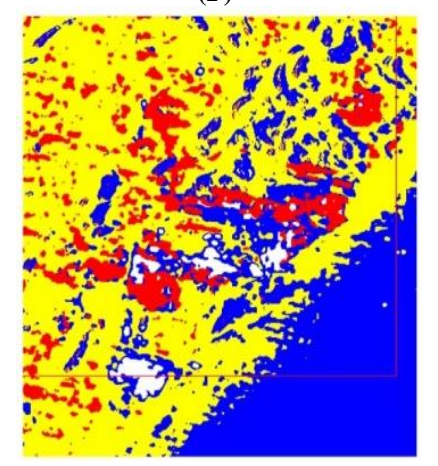$$
\text { . }
$$ 
Table 1: Comparison of Backscattering Coefficient Values for Sigma, Beta $_{0}$ and $\mathrm{Gamma}_{0}$ in $\mathrm{HH}$ and VV Polarization

\begin{tabular}{|c|c|c|c|}
\hline \multirow{2}{*}{ Class } & \multicolumn{3}{|c|}{$\mathrm{HH}$} \\
\hline & SIGMA $_{0}$ & BETA $_{0}$ & GAMMA $_{0}$ \\
\hline \multirow{5}{*}{ Urban } & 3.278902 & 7.475886 & 3.618423 \\
\hline & -1.859742 & 2.707253 & -1.577046 \\
\hline & 2.912314 & 4.842838 & 1.121864 \\
\hline & 2.908115 & 6.702393 & 3.328928 \\
\hline & 1.950598 & 6.135697 & 2.292138 \\
\hline \multirow[t]{2}{*}{ Average } & 1.838037 & 5.572813 & 1.756861 \\
\hline & -7.388383 & -2.260189 & -7.173384 \\
\hline \multirow{4}{*}{$\begin{array}{l}\text { Vegeta- } \\
\text { tion }\end{array}$} & -9.453182 & -5.582003 & -9.05334 \\
\hline & -7.536016 & -3.020662 & -7.246042 \\
\hline & -9.26615 & -5.383613 & -8.868596 \\
\hline & -7.428163 & -3.214823 & -7.091397 \\
\hline \multirow[t]{3}{*}{ Average } & -8.214379 & -3.892258 & -7.886552 \\
\hline & -8.414556 & -4.294729 & -7.903994 \\
\hline & -7.495234 & -3.508544 & -7.118017 \\
\hline \multirow[t]{3}{*}{ Bare soil } & -4.725541 & -0.498438 & -4.391076 \\
\hline & -7.428163 & -3.214823 & -7.091397 \\
\hline & -8.6601 & -4.547241 & -8.306013 \\
\hline \multirow[t]{3}{*}{ Average } & -7.344719 & -3.212755 & -6.962099 \\
\hline & -12.737518 & -7.499757 & -12.369368 \\
\hline & -13.358795 & -8.702394 & -12.990115 \\
\hline \multirow[t]{3}{*}{ Water } & -12.926671 & -8.254375 & -12.558025 \\
\hline & -12.287419 & -7.185877 & -11.918825 \\
\hline & -13.079679 & -8.894231 & -12.710858 \\
\hline Average & -12.878016 & -8.107327 & -12.509438 \\
\hline
\end{tabular}

\begin{tabular}{llll}
\hline \multirow{2}{*}{ Class } & & \multicolumn{1}{c}{ VV } & \\
& SIGMA $_{0}$ & SIGMA $_{0}$ & SIGMA $_{0}$ \\
\hline \multirow{2}{*}{ Urban } & -2.801567 & -2.801567 & -2.801567 \\
& -4.147142 & -4.147142 & -4.147142 \\
Average & -4.970873 & -4.970873 & -4.970873 \\
& -2.803524 & -2.803524 & -2.803524 \\
Vegeta- & -3.18429 & -3.18429 & -3.18429 \\
tion & -3.581479 & -3.581479 & -3.581479 \\
& -5.180068 & -5.180068 & -5.180068 \\
Average & -6.615044 & -6.615044 & -6.615044 \\
& -5.630527 & -5.630527 & -5.630527 \\
Bare soil & -6.829117 & -6.829117 & -6.829117 \\
& -6.553156 & -6.553156 & -6.553156 \\
\multirow{2}{*}{ Average } & -6.161582 & -6.161582 & -6.161582 \\
& -6.882872 & -6.882872 & -6.882872 \\
& -6.101486 & -6.101486 & -6.101486 \\
Water & -4.679021 & -4.679021 & -4.679021 \\
& -6.553156 & -6.553156 & -6.553156 \\
Average & -7.278573 & -7.278573 & -7.278573 \\
& -6.299022 & -6.299022 & -6.299022 \\
& -9.490918 & -9.490918 & -9.490918 \\
& -10.033097 & -10.033097 & -10.033097 \\
& -9.88018 & -9.88018 & -9.88018 \\
& -9.285248 & -9.285248 & -9.285248 \\
& -10.079844 & -10.079844 & -10.079844 \\
& -9.753857 & -9.753857 & -9.753857 \\
\hline
\end{tabular}

Table 2: Accuracy Assessment for Various Classifications

\begin{tabular}{lll}
\hline $\begin{array}{l}\text { Supervised Classification Meth- } \\
\text { od }\end{array}$ & $\begin{array}{l}\text { Overall Accura- } \\
\text { cy }\end{array}$ & $\begin{array}{l}\text { Kappa Coeffi- } \\
\text { cient }\end{array}$ \\
\hline Parallelepiped & 97.653 & 0.969 \\
Minimum Distance & 90.614 & 0.874 \\
Mahalanobis & 95.487 & 0.939 \\
Maximum Likelihood & 98.0144 & 0.9734 \\
Binary Coding & 74.007 & 0.647 \\
Support Vector Machine & 99.459 & 0.993 \\
\hline
\end{tabular}

The zoomed views of Betao image, Sigma image and Gamma output image of $\mathrm{HH}$ polarization have been shown in fig. 5 . Similarly the zoomed views of the Betao image, Sigman image and Gamma output image of VV polarization have been shown in fig. 6. The final incidence angle image which is calculated after all arithmetic operations are done, Beta 0 image, Sigma image and Gamma output image for $\mathrm{HH}$ polarization have shown in fig. 7. The final incidence angle image which is calculated after all the arithmetic operations are done. Beta $0_{0}$ image, Sigma image and Gamma output image for VV polarization have been shown in fig. 8. In table 2 , the back scattering coefficient values for various textures like water, settlement, agriculture and bare soil fields have been listed [8]. The amplitude SAR data is further analyzed using various classification algorithms and accuracy details are shown in table 2. The Support Vector Machine classification algorithm has given an overall accuracy of $98.0144 \%$, and kappa coefficient 0.9734 [9]. It is a better classification algorithm compared to other supervised classification algorithms.

\section{Conclusion}

The backscattering coefficient values Sigma naught, Beta naught and Gamma naught of dual polarization $\mathrm{HH}$ and VV polarimetric SAR data sets of ENVISAT-ASAR sensor have been calculated and observed that these values are very low for water bodies because of surface scattering, low for barren fields and agriculture fields because of volume scattering and high for man-made settlements because of double bounce scattering effect as shown in the table 1. It is also observed that the backscattering coefficient values of $\mathrm{HH}$ polarization are high compared to the backscattering coefficient values obtained with VV polarization. Higher backscattering coefficient values have been obtained for the urban class $(1.838037,5.572813$ and 1.756861 of Sigma naught, Beta naught and Gamma naught respectively) compared to the remaining classes vegetation, bare soil and water selected in the present study. With these data sets, the better land use land cover classification accuracy of the study area is obtained with supervised Support Vector Machine classifier (Over all Accuracy of $99.459 \%$ and Kappa Coefficient of 0.993) compared to the accuracy results obtained with the remaining supervised classification algorithms implemented in the present study.

\section{References}

[1] C.-P. Tan J.-Y. Koay, K.-S. Lim, H.-T. Ewe and H.-T.Chuah Classification of Multi-Temporal SAR Images for Rice Crops using Combined Entropy Decomposition And Support Vector Machine Technique [Journal] // Progress In Electromagnetics Research, PIER. - 2007. - 71. - pp. 19-39.

[2] Y. Murali Mohan Babu M. V. Subramanyam and M.N Giri Prasad Generation of Back Scatter Image for MRS Mode RISAT-1 Data [Journal]. - 2014

[3] Y. S. Rao Shaunak De, Vineet Kumar and Anup Das Full and Hybrid Polarimetric SAR Data Analysis for Various Land [Journal] // International Experts Meet on Microwave Remote Sensing. - Ahmadabad: India Features, 16-17 December 2013.

[4] Cloude S. E. An entropy based classification scheme for land applications of polarimetric SAR [Journal] // IEEE, 3(1). - 1997. - pp. 68-78.

[5] D. Chakraborty S. Thakur and A. Jeyaram, YVN Krishna Murthy, VK Dadhwal Texture Analysis for Classification of RISAT-II IMAGES [Journal] // XXII ISPRS Congress. - Melbourne, Australia: [s.n.], 25 August - 01 September 2012

[6] H. Laur P. Bally, P. Meadows, J. Sanchez, B. Schaettler, E. Lopinto and D. Esteban ERS SAR CALIBRATION, ESA [Journal]. - 5 November 2004. - 5.

[7] Lee J. S., M. R. Grunes, E. Pottier, et el Unsupervised terrain classification preserving polarimetric scattering characteristics [Journal] // IEEE Transactions on Geoscience and Remote Sensing. - 2004. 4: Vol. 42. - pp. $722-731$

[8] Mitchell Dariusz Stramski and Rick A. Reynolds and B. Greg Relationships between the backscattering coefficient, Beam attenuation coefficient and particulate organic Matter concentrations in the ross sea [Journal] // Ocean Optics XIV. - 1998

[9] Mountrakis G., Im, L., Ogole, C., Support Vector Machines in Remote Sensing- A review [Journal] // ISPRS J. of Photogramm. and Remote Sen.. - 2011. - 66. - pp. 247-259. 